Agropedology 2016, 26 (02), 237-241

\title{
Assessment of Physico-chemical Parameters and Nutrient Availability in Soils of Arvi and Karanja Blocks of Wardha district, Maharashtra
}

\author{
Aliza Pradhan*, Mahesh Maske, Manoj Sayre and Mahesh Sadatpure
}

M. S. Swaminathan Research Foundation, Chennai, Tamil Nadu - 600113, India

\begin{abstract}
The physical and chemical properties of the soil governs the kand productivity The present study focuses on soil properties and nutrient indices of soils in five different villages of Arvi and Karanja blocks of Wardha district, Maharashtra. A research programme on Leveraging Agriculture for Nutrition in South Asia (LANSA) through framing system is in progress in these villages. The soils of the site are slightly acidic to alkaline, medium to high in organic carbon, deficient in nitrogen, phosphorus and zinc, medium in iron content and sufficient in potassium, copper and manganese content.
\end{abstract}

Keywords: soil parameters, micronutrients, nutrient indices

\section{Introduction}

Physico-chemical properties of soils has a strong bearing on plant nutrient availability. The emerging widespread deficiency of macronutrients specifically nitrogen, phosphorus and in some cases potassium but also micronutrients has been reported in Indian soils. Deficiency of micronutrients during the last three decades has grown in both, magnitude and extent because of increased use of high analysis fertilizers, use of high yielding crop varieties and increase in cropping intensity causing decline in crop productivity and sustainability (Yadav and Meena, 2009). Thus there is an urgent need for correction of individual nutrient deficiency and for arresting its further spread. Furthermore, assessment of soil nutrient status plays pivotal role in planning and implementation of a sustainable agricultural production system. Accordingly, the present study was undertaken in five villages of Wardha district of Maharashtra, where a Farming System for Nutrition (FSN) study under a research programme on Leveraging Agriculture for Nutrition in South Asia (LANSA) is in progress. As the farming systems for nutrition envisages introduction of agricultural remedies to the nutritional

*Corresponding Author (Email: aliza@mssrf.res.in) maladies prevailing in an area through mainstreaming nutritional criteria in the selection of the components of a farming system (Nagarajan et al. 2014), an assessment of soil sample is a must for successful implementation of the study programme. This paper presents an assessment of the physico-chemical properties of soils along with their nutrient indices, to support planning of farming system interventions.

\section{Material and Methods \\ Study site}

The study site (Wardha district) of Maharashtra lies between $20^{\circ} 28^{\prime} \mathrm{N}$ and $21^{\circ} 21^{\prime} \mathrm{N}$ latitude and $78^{\circ} 4^{\prime} \mathrm{E}$ and $79^{\circ}$ 15 ' E longitudes. The district covers 6,039 sq. $\mathrm{km}$ accounting to 2.06 percent of the state and is characterized by hot, dry, and sub-humid bio-climate with dry summers and mild winters. The district comprises of eight tehsils or blocks viz., Ashti, Karanja, Arvi, Seloo, Wardha, Deoli, Hingalghat and Samudrapur. The district receives $1062.8 \mathrm{~mm}$ annual rainfall of which $85 \%$ is contributed by south-west monsoon but its distribution is erratic. Review of agro-ecological of the rain but its erratic distribution. Further, the extent of soil loss in the district due to erosion is estimated to be of the order of 19.6 lakh tonnes per annum (Rukmani and Manjula, 2009) 
which is well above the maximum permissible limit of 10 tonnes per hectare per annum. The district is dominated by black soils, classified into Kanhar (Heavy soils), Madhyam (Medium soils) and Bardi (Lights soils) covering 35.4, 43.0 and $20.6 \%$, respectively.

\section{Sample collection and analysis}

A total of 55 surface soil samples $(0-15 \mathrm{~cm})$ were collected from five villages of Wardha district viz., Saheli and Bitpur (Arvi block), Borgaon/Gondi, Susund, and Heti (Karanja block) during 2014-15. Collected soil samples were air dried and processed for laboratory analysis.. The sand, silt, clay in soil were analyzed by bouyoucos hydrometer method. Soil pH, EC, organic carbon (OC), available nitrogen, phosphorus and potassium were estimated by the standard procedures as described by Jackson (1973). The available micronutrients i.e. zinc, iron, copper and manganese in these soil samples were extracted with DTPA solution (Lindsey and Norvell, 1978) and the concentration of nutrients was determined on Atomic Absorption Spectrophotometer. The soil nutrient index was calculated according to the procedure suggested by Ramamoorthy and Bajaj (1969).

\section{Results and Discussion}

The texture, of the soil varied in different villages (Table 1). The $\mathrm{pH}$ of the soils ranged from 6.4 to 8.7 and EC from 0.12 to $0.46 \mathrm{dS} \mathrm{m}^{-1}$ (Table 1). The organic carbon content varied from 0.52 to 2.24 percent (Table 1). This medium to high content of organic carbon might be due to addition of organic matter mainly through crop residue, farm yard manure etc.

Table 1. Physico-chemical parameters of soils of Wardha district

\begin{tabular}{|c|c|c|c|c|c|c|c|c|}
\hline \multirow{2}{*}{$\begin{array}{l}\text { Name of } \\
\text { Tahsil }\end{array}$} & \multirow{2}{*}{$\begin{array}{l}\text { Name of } \\
\text { village }\end{array}$} & \multirow{2}{*}{$\begin{array}{l}\text { Soil } \\
\text { texture* }\end{array}$} & \multicolumn{2}{|l|}{$\mathrm{pH}(1: 2.5)$} & \multicolumn{2}{|c|}{$\mathrm{EC}\left(\mathrm{dS} \mathrm{m} \mathrm{m}^{-1}\right)$} & \multicolumn{2}{|c|}{ Organic carbon $\left(\mathrm{g} \mathrm{kg}^{-1}\right)$} \\
\hline & & & Range & Mean \pm SD & Range & Mean \pm SD & Range & Mean \pm SD \\
\hline \multirow[t]{2}{*}{ Arvi } & Saheli & 1 & $6.90-8.70$ & $7.31 \pm 0.38$ & $0.12-0.26$ & $0.20 \pm 0.04$ & $0.83-1.7$ & $1.13 \pm 0.25$ \\
\hline & Vitpur & $\mathrm{c}$ & $6.82-8.14$ & $7.41 \pm 0.41$ & $0.17-0.34$ & $0.22 \pm 0.06$ & $0.95-1.84$ & $1.32 \pm 0.32$ \\
\hline \multirow[t]{3}{*}{ Karanja } & Susund & $\mathrm{cl}, \mathrm{scl}$ & $7.29-7.96$ & $7.58 \pm 0.21$ & $0.20-0.46$ & $0.32 \pm 0.09$ & $0.64-2.24$ & $1.24 \pm 0.44$ \\
\hline & Heti & $\mathrm{scl}, 1$ & $6.40-7.84$ & $7.34 \pm 0.44$ & $0.12-0.43$ & $0.26 \pm 0.12$ & $0.52-1.73$ & $1.11 \pm 0.42$ \\
\hline & Borgaon & $1, \mathrm{sl}$ & $6.87-7.88$ & $7.54 \pm 0.31$ & $0.18-0.33$ & $0.25 \pm 0.05$ & $0.76-1.78$ & $1.29 \pm 0.33$ \\
\hline
\end{tabular}

* 1, loam; c, clay; cl, clay loam; scl, silty clay loam; sl, silt loam

The available nitrogen content in soils of Wardha ranged deficient in phosphorus (Table 2). The available K content of from 70.4 to $153.5 \mathrm{~kg} \mathrm{ha}^{-1}$ indicating nitrogen deficiency in soils ranged from 56.7 to $669.6 \mathrm{kgha}^{-1}$ and 71 percent of the the area. The available $P$ content of soils ranged from 1.4 to soils showed sufficiency in K content (Table 2). $31.6 \mathrm{ppm}$ and 83.6 percent of soil samples were found to be

Table 2. Status of major nutrients in soils of Wardha district

\begin{tabular}{llllllll}
\hline \multirow{2}{*}{$\begin{array}{l}\text { Name } \\
\text { of } \\
\text { Blocks }\end{array}$} & $\begin{array}{l}\text { Name of } \\
\text { village }\end{array}$ & \multicolumn{2}{c}{ Available N $\left(\mathrm{kg} \mathrm{ha}^{-1}\right)$} & \multicolumn{2}{c}{ Available P $\left(\mathrm{kg} \mathrm{ha}^{-1}\right)$} & \multicolumn{2}{c}{ Available K $\left.(\mathrm{kg} \mathrm{ha})^{-1}\right)$} \\
\cline { 3 - 8 } & & & Mean \pm SD & Range & Mean \pm SD & Range & Mean \pm SD \\
\hline Arvi & Saheli & $70.37-102.36$ & $93.35 \pm 9.47$ & $1.75-4.25$ & $2.77 \pm 0.65$ & $210.00-448.30$ & $340.32 \pm 66.23$ \\
& Vitpur & $70.37-95.96$ & $84.00 \pm 10.17$ & $1.37-7.31$ & $3.38 \pm 2.03$ & $178.00-437.40$ & $320.55 \pm 68.47$ \\
Karanja & Susund & $60.78-153.54$ & $113.88 \pm 24.04$ & $3.87-26.87$ & $10.13 \pm 7.85$ & $98.20-589.30$ & $335.70 \pm 133.99$ \\
& Heti & $89.56-137.54$ & $109.63 \pm 13.80$ & $1.94-31.62$ & $14.73 \pm 9.62$ & $56.67-669.60$ & $332.31 \pm 225.65$ \\
& \multirow{2}{*}{ Borgaon } & $83.17-118.35$ & $102.36 \pm 10.51$ & $4.56-17.31$ & $9.74 \pm 5.79$ & $156.00-442.10$ & $300.77 \pm 97.40$ \\
\hline
\end{tabular}


The DTPA-Zn in soils ranged from 0.20 to $2.16 \mathrm{mg}$ $\mathrm{kg}^{-1}$ (Table 3). About 50.9 percent of samples were deficient while 41.8 percent samples were in medium category indicating widespread deficiency of zinc in the area. The deficiency of zinc was observed in Bitpur and Saheli followed by Susund, Borgaon/Gondi, and Heti. The low availability of zinc in these soils might be due to alkaline soil reaction as zinc cations are changed largely to their oxides or hydroxides under alkaline conditions and thereby lowering the availability (Meena et al. 2006). The widespread deficiency of zinc in intensively cultivated districts of Maharashtra having alkaline, calcareous, black clay soils have also been reported (Patil and Kharche, 2006; Katkar et al., 2013; Mandavgade et al., 2015).

The DTPA-Fe content showed a wide range of variation (5.68 to $44.1 \mathrm{mg} \mathrm{kg}^{-1}$ ) in the soils of different villages (Table 3 ). Majority of soil samples were moderately high to high $(72.8 \%)$ whereas 21.8 percent were found to be very high in Fe content. The high Fe content in soil might be due to presence of minerals like feldspar, magnetite, haematite, and limonite which constitute bulk of trap rock in these soils (Vijaya Kumar et al., 2013). Few soil samples collected from Saheli and Borgaon/Gondi were found to be low in iron status $(7 \%)$.

Table 3. Status of DTPA-extractable micronutrients in soils of Wardha district

\begin{tabular}{|c|c|c|c|c|c|c|c|c|c|}
\hline \multirow{2}{*}{$\begin{array}{l}\text { Name } \\
\text { of tehsil }\end{array}$} & \multirow[t]{2}{*}{ village } & \multicolumn{2}{|c|}{$\mathrm{Zn}\left(\mathrm{mg} \mathrm{kg}^{-1}\right)$} & \multicolumn{2}{|c|}{$\mathrm{Fe}\left(\mathrm{mg} \mathrm{kg}^{-1}\right)$} & \multicolumn{2}{|c|}{$\operatorname{Mn}\left(\mathrm{mg} \mathrm{kg}^{-1}\right)$} & \multicolumn{2}{|c|}{$\mathrm{Cu}\left(\mathrm{mg} \mathrm{kg}^{-1}\right)$} \\
\hline & & Range & Mean \pm SD & Range & Mean \pm SD & Range & Mean \pm SD & Range & Mean \pm SD \\
\hline \multirow[t]{4}{*}{ Arvi } & Saheli & $0.30-$ & $0.48 \pm 0.13$ & $5.68-$ & $16.89 \pm 7.88$ & $13.60-$ & $34.71 \pm 16.43$ & $2.20-$ & $3.48 \pm 0.89$ \\
\hline & & 0.72 & & 29.90 & & 60.36 & & 4.96 & \\
\hline & Vitpur & $0.26-$ & $0.45 \pm 0.14$ & $9.08-$ & $19.36 \pm 8.83$ & $15.10-$ & $43.55 \pm 0.66$ & $3.04-$ & $4.18 \pm 0.86$ \\
\hline & & 0.72 & & 32.50 & & 73.78 & & 5.80 & \\
\hline \multirow[t]{6}{*}{ Karanja } & Susund & $0.38-$ & $0.80 \pm 0.32$ & $10.08-$ & $18.35 \pm 6.93$ & $21.94-$ & $41.97 \pm 20.36$ & $3.22-$ & $5.83 \pm 2.11$ \\
\hline & & 1.48 & & 27.82 & & 90.56 & & 8.86 & \\
\hline & Heti & $0.36-$ & $0.96 \pm 0.56$ & $11.80-$ & $23.49 \pm 10.56$ & $20.34-$ & $54.1 \pm 28.03$ & $3.74-$ & $6.41 \pm 1.95$ \\
\hline & & 2.16 & & 44.10 & & 109.14 & & 9.58 & \\
\hline & Borgaon & $0.20-$ & $0.84 \pm 0.77$ & $7.70-$ & $18.06 \pm 9.42$ & $16.62-$ & $39.92 \pm 22.60$ & $2.54-$ & $5.19 \pm 1.54$ \\
\hline & & 3.02 & & 34.40 & & 102.16 & & 6.44 & \\
\hline
\end{tabular}

The DTPA-Cu content ranged from 2.2 to $9.58 \mathrm{mg} \mathrm{kg}^{-1}$ indicating its sufficiency in the soils, which might be due to higher biological activities in these soils and chelating effect (Jibhakate et al., 2009). DTPA-Mn ranged from 13.6$109.14 \mathrm{mg} \mathrm{kg}^{-1}$ suggesting its status as very high (Table 3). The relative high content of $\mathrm{Mn}$ in these soils could be due to the soils derived from basaltic parent material which contains higher ferromagnesian minerals (Mandavgade et al., 2015).

The nutrient indices (Table 4) indicate low for nitrogen (1.00), phosphorus (1.16), zinc (1.56), medium for iron (1.71) and high for potassium (2.67), copper (3.00) and manganese (3.00).

Table 4. Status of nutrient and nutrient indices in soils of Wardha district

\begin{tabular}{lccccc}
\hline Nutrients & \multicolumn{3}{c}{ Percent samples } & \multirow{2}{*}{$\begin{array}{c}\text { Nutrient index } \\
\text { value (NIV) }\end{array}$} & Rating* \\
\cline { 2 - 4 } & Low & Medium & High & & \\
\hline $\mathrm{N}$ & 100 & - & - & 1.00 & Low \\
$\mathrm{P}$ & 83.6 & 16.4 & - & 1.16 & Low \\
$\mathrm{K}$ & 3.6 & 25.4 & 71.0 & 2.67 & High \\
$\mathrm{Zn}$ & 50.9 & 41.8 & 7.3 & 1.56 & Low \\
$\mathrm{Fe}$ & 36.4 & 56.4 & 7.2 & & 1.71 \\
$\mathrm{Cu}$ & - & - & 100 & 3.00 & Medium \\
$\mathrm{Mn}$ & - & - & 100 & 3.00 & High \\
\hline
\end{tabular}

*NIV: <1.66 (Low); 1.66-2.33 (Medium); >2.33 (High). 


\section{Conclusion}

The soils of Arvi and Karanja blocks of Wardha district are slightly acidic to alkaline in soil reaction, nonsaline, medium to high in organic carbon. These soils are deficient in nitrogen, phosphorus and zinc while medium in iron content and sufficient in potassium, copper and manganese. The assessment of nutrient is being used for suggesting improved package and practices of crop production through integrated nutrient management under the FSN study, to promote better soil health and crop productivity.

\section{References}

Jackson M.L. (1973). Soil Chemical analysis, Prentice Hall of India Private Ltd. New Delhi.

Jibhakate S.B., Raut M.M., Bhende S.N. and Kharche V.K. (2009). Micronutrient status of soils of Katol tahasil in Nagpur district and their relationship with some soil properties. Journal of Soils and Crops 19, 143146.

Katkar R.N., Lakhe S.R., Kharche V.K., Laharia G.S., Sadavarte S.G., et al. (2013). Micronutrient mapping in soils of Wardha district, Maharastra. Agropedology 23(2), 113-117.

Lindsay W.L. and Norvell W.A. (1978). Development of DTPA soil test for Zn, Fe, Mn and Cu. Soil Science Society of America Journal 42, 421-428.

Mandavgade R.R., Waikar S.L., Dhamak A.L. and Patil V.D. (2015). Evaluation of micronutrient status of soils and their relation with some chemical properties of soils of northern Tahsils (Jintur, Selu and Pathri) of Parbhani district. Journal of Agriculture and Veterinary science 8 (2), 38-41.
Meena H.B., Sharma R.P. and. Rawat U.S. (2006). Status of macro and micronutrients in some soils of Tonk district of Rajasthan. Journal of the Indian Society of Soil Science 54, 508-512.

Patil J.D. and Kharche V.K. (2006). Micronutrients deficiency in soils of Western Maharashtra. Indian Journal of Fertilisers 2, 55-58.

Nagarajan S., Bhavani R.V. and Swaminathan M.S. (2014). Operationalizating the concept of farming system for nutrition through the promotion of nutritionsensitive agriculture. Current Science 107 (6), 959964.

Ramamoorthy B. and Bajaj J.C. (1969). Available N, P and K status of Indian soils. Fertilizer News 14, 24-26.

Rukmani R. and Manjula M. (2009). Designing rural technology delivery systems for mitigating agricultural distress: A study of Wardha district.MS Swaminathan Research Foundation, Chennai and Office of the Principal Scientific Adviser to the Government of India, New Delhi.

Shen J., Yuan L., Zhang J., Li, H., Bai Z., et al. (2011). Phosphorus dynamics: From soils to plant. Plant physiology 1 56, 997-1005.

Vijaya kumar M., Lakshmi G.V. and Madhuvani P. (2013). Appraisal of soil fertility status in salt affected soils of ongole division, Prakasam district of Andhra Pradesh. Journal of the Indian Society of Soil Science 61,333-340.

Yadav R.L., and Meena M.C. (2009). Available micronutrient status and their relationship with soil properties of Degana soil series of Rajasthan. Journal of the Indian Society of Soil Science 57, 9092. 
Agropedology

A journal for publication

of original research

articles on all aspects of

pedology and edaphology

Volume 26

December (No. 2)

2016

Research Articles

Delineation of Land Management Units in Tropical South Deccan Plateau of India

105-116

V. Ramamurthy, K.M. Nair, S.C. Ramesh Kumar, S. Srinivas,

L.G.K. Naidu, K. Sujatha, Dipak Sarkar and S.K. Singh

Soil Site Suitability Evaluation of Major Crops for Sustainable Land Use

Planning in Kupti Watershed, Yavatmal District, Maharashtra

A.J. Patangray, N.G. Patil, S.K. Singh, P. Tiwari, V. N. Mishra, A.R. Pagdhune and B.A. Patil

117-131

Effect of Phosphorous Application on Uptake, Yield and Fertilizer

Use Efficiency under Rice-Rice and Rice-Sunflower Systems in High PSoils

132-148

A. Srinivas, P. Surendra Babu, A. Madhavi, G.E.C.H. Vidyasagar and G. R. Maruthi Sankar

Soil Mapping at Village level in a Part of Amethi District, U. P., Using IRS LISS-IV and

Cartosat-1 Merged Data for Sustainable land and Crop Management

PPS Yadav, G. Rajput, Arjun Singh and K. Singh

149-163

Effects of Salinity on Germination Behaviour of Two Paddy Land Races

Grown in Chakrata (Dehradun), Uttarakhand, India

Ranbeer Singh Chauhan, J.S. Chauhan, A.S. Rawat and Dinesh Singh Rawat

164-171

Pre Harvest Losses as Perceived by the Wheat Growers in Madhya Pradesh-An Economic Analysis

172-177

S.C. Meena, Deepak Rathi and Hari Om Sharma

Characterization, Classification and Evaluation of Cashew Growing

Soils in Coastal Odisha for Sustainable Production

178-188

R. Srinivasan, S.K. Singh, D.C. Nayak and L.G.K. Naidu

The Major Biophysical Indicators of Desertification in Arid and Semi arid regions of India

189-197

S. Dharumarajan, M. Lalitha, R. Vasundhara and Rajendra Hegde

Characterization and Classification of Different Rice Growing Soils with Special

Emphasis on Soil Organic Carbon Stock in Rajnagar Block of Birbhum District, West Bengal

198-207

Shreyasi Gupta Choudhury, Tapati Banerjee, Krishnendu Das, A.K. Sahoo, D.C. Nayak and S.K. Singh

Assessment of Soil Degradation and Large Scale Soil Mapping Using GIS: A Case

Study of Village Ramagarh from Purna Valley, Maharashtra

R.K. Naitam, V.K. Kharche, V.V. Gabhane, T. Bhattacharyya, S.M. Taley,

I.K. Ramteke, Preeti Deshmukh and N.M. Konde

Climatic Suitability Assessment for Groundnut (Arachis hypogaea)

in Alfisols of Karnataka - a Regression Approach

H.S. Shivaramu, P. Vijaya Kumar, M.B. Rajegowda, V.U.M. Rao, N. A. Janardhana Gowda and D. V. Soumya

Characterization and Formation of Salt affected Soils in Eastern Rajasthan Upland

230-236

S.S. Sharma, R.P. Sharma, R.S. Singh and S.K. Singh

Short Communication

Assessment of Physico-Chemical Parameters and Nutrient Availability in Soils of

Arvi and Karanja Blocks of Wardha district, Maharashtra

237-240

Aliza Pradhan, Mahesh Maske, Manoj Sayre and Mahesh Sadatpure 


\title{
INDIAN SOCIETY OF SOIL SURVEY AND LAND USE PLANNING \\ (Registered under Act XXI of 1860) \\ Registration No. Maharashtra, 301/87, Nagpur \\ FOUNDED - 1986 \\ EXECUTIVE COUNCIL FOR 2014-2016
}

\author{
President \\ Vice Presidents \\ : Dr. Arun Chaturvedi \\ Honorary Secretary
Joint Secretaries \\ : $\quad$ Dr. T. N. Hajare \\ Dr. G. Ravindra Chary \\ : $\quad$ Dr. G.P. Obi Reddy \\ : Dr. K. Karthikeyan \\ Dr. V. V. Gabhane \\ Treasurer \\ Councillors \\ : $\quad$ Shri. S.S. Gaikwad \\ : $\quad$ Dr. Ashok Kumar Singh, Dr. Subhash Chand (Northern Zone) \\ Dr. Guru Prasad Gupta, Dr. Pravin H. Vaidya (Central Zone) \\ Dr. S. Thayalan, Dr. M.V.S. Naidu (Southern Zone) \\ Dr. Samiron Dutta, Dr. Krishendu Das (Eastern Zone) \\ Dr. P. Raja, Dr. R.P. Sharma (Western Zone) \\ Members (Past Presidents \\ Ex-Officio) \\ : Dr. A.R. Kalbande, Dr. M. Velayutham, Dr. K.S. Gajbhiye, \\ Dr. R.K. Saxena, Dr. S.B. Deshpande, Dr. A.K. Maji, \\ Dr. Dipak Sarkar

\section{Editorial Board \\ Chief Editor \\ Members} \\ : $\quad$ Dr. N.G. Patil \\ : Dr. S. Vadivelu \\ Dr. G.S. Sidhu \\ Dr. A.K. Srivastava \\ Dr. H.S. Shivaramu \\ Dr. Vilas Kharche \\ Dr. P. Chandran \\ Dr. M.S.S. Nagaraju \\ International Consulting \\ Editors \\ : $\quad$ Dr. A.R. Marmut (Canada), Dr. P.K. Patra (Japan), \\ Dr. Lallan Singh (Nigeria)
}

\section{JOURNAL OF}

THE INDIAN SOCIETY OF SOIL SURVEY AND LAND USE PLANNING

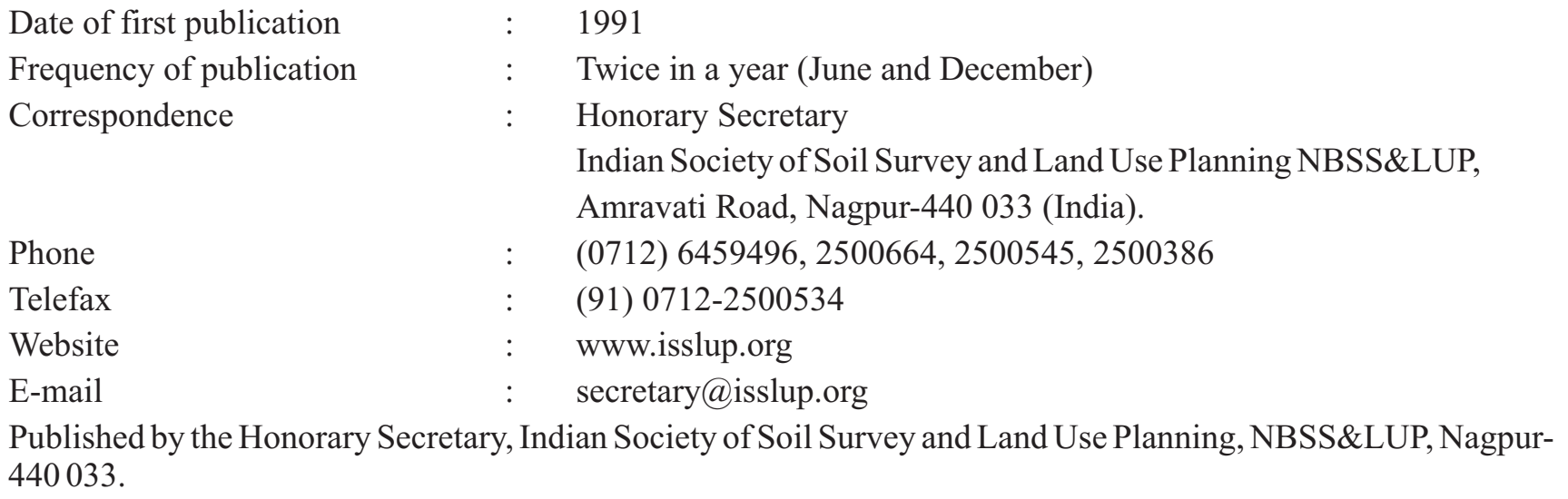

Published by the Honorary Secretary, Indian Society of Soil Survey and Land Use Planning, NBSS\&LUP, Nagpur440033. 


\section{ACKNOWLEDGEMENT}

Sincere thanks are placed on record to the Indian Council of Agricultural Research, New Delhi for the grant of financial support for the publication of 'Agropedology'. 


\section{Instructions for the Preparation of Manuscript for Agropedology}

Prospective authors(s) is/are advised to consult the latest issue of the Journal to get acquainted with details of its format and style.

\section{General}

Papers, communicated by the members of the society, will be considered for publication if they make an original contribution to the knowledge in any branch of soil science, notably soil genesis, soil morphology and classification; soil physics and hydrology; soil chemistry and mineralogy; soil and water management and conservation. The journal particularly welcomes papers that promote understanding of soil in the Indian sub-continent.

Full-length articles, short communications and invited review articles that indicate fruitful areas of further research and innovative are published in the Journal. Reviews may be restricted to 25 printed pages in length ( 50 pages A4 doublespaced type).

All papers are reviewed. No free prints are provided; pdf of papers will be supplied on request.

At the initial stage, the manuscripts may be submitted in hard copy format. When the manuscript is returned to the authors with the referee's reports for revision, the editor will make notes on presentation, layout and general matters concerning style, and these should be incorporated into the revised paper. A disc will be requested once the paper is accepted in principle. The version on the disk should be identical to the one in the hard copy. Please give the name of the file and the word-processing package used. While returning the revised manuscript, a DISCUSSION SHEET quoting each question raised by the Reviewers followed by the answers may be provided. Authors may also indicate where (page Nos. in the revised manuscript) and how the revision has been done. Authors may also indicate the reasons, if they do not agree to the reviewer's comments.

Original illustrations will be returned after

publication if a request to this effect is made at the time of submission.

Submission of a paper means that the results reported by the author in that paper have not been published and are not being considered for publication elsewhere.

The Journal assumes that all authors of a multiauthored paper agree to its submission. It takes no responsibility for fraud or inaccuracy on the part of the contributors.

\section{Manuscript}

The work should be presented in concise and clear English. Generally, the length of a Full- length article should not exceed 3000 words and that of Short communication should be within 750 words.

\section{Organisation of the Manuscript}

A full length article comprises the following sections.

a) Short title b) Title

c) Author (s)

d) Institution and address with PIN code

e) Abstract (along with keywords)

f) Introduction

g) Materials and Methods h) Results and Discussion i) Conclusion

j) Acknowledgements (if any)

k) References

1) Table and figures (if any)

Guidelines for each section are as follows:

All the aforementioned headings should start from left hand side of the margin, without any indent.

Short Title : A shortened title (approximately of 50 characters) set in capital letters should convey the main theme of the paper.

Title : This should be concise and appropriately informative and should contain all keywords necessary to facilitate retrieval by searching techniques.

Author/Authors : The name(s) of author(s) should be typed in capital letters a little below the title starting from the left margin.

Institutional address : The matter will come below the name (s) of the author(s). Complete postal address with PIN code should be furnished. In case, any author has left the above address, this could be indicated as a footnote.

Abstract : The abstract (preferably less than 200 words) should not just recapitulate the results but should state concisely the scope of the work and give the principal findings. It should be complete enough for direct use by abstracting services. Acronyms and references should be avoided. 
Additional keywords : Up to six keywords not contained in the title may be listed beneath the abstract to assist searching techniques.

Introduction : This section is meant to introduce the subject of the paper. The introduction should be short and concise and should not exceed what is necessary to indicate the reasons for the work and its essential background.

Materials and Methods : Geographical position of soil-site or soil used in the experiment or site of field-trial should be mentioned with the help of coordinates (latitude and longitude).

Sufficient experimental details, such as, the materials used in the investigation, methods of experiment and analysis adopted should be given to enable repetition of the work. Proper classification of soils must invariably be indicated at the level of Order/ Suborder/ Greatgroup/ Subgroup as per Soil Taxonomy (USDA).

Results and Discussion : The Results should be reported in the form of salient points of observation and critical interpretation thereof whereas the Discussion should explain the significance of the results rather than recapitulate them.

Conclusion : This is an extremely important section which the author(s) should articulate in the form of a clearly crystallized summary of the results obtained alongwith their implications in solution of the practical problems or contributions to the advancement of the scientific knowledge.

References should be cited chronologically in the text. All references in the text must be listed at the end of the paper, with the names of authors arranged alphabetically; all entries in this list must correspond to references in the text. In the text, the names of two co-authors are linked by 'and'; for three or more, the first author's name is followed by 'et al'. No editorial responsibility can be taken for the accuracy of the references; authors are requested to check these with special care. Titles must be included for all the references. Papers that have not been accepted for publication may not be included in the list of references and must be cited as 'unpublished data' or as 'personal communication'; the use of such citations are discouraged.

Provide titles of books and journals in full. The journal title should be in the italics.

\section{Examples :}

\section{Journal article}

Buyanovsky, G.A., Aslam, M., and Wagner, G.H. (1994). Carbon turnover in soil physical fractions. Soil Science Society of America Journal 58, 1167-1173.

\section{Chapter in book}

Oades, J.M. (1998). An introduction to organic matter in mineral soils. In 'Minerals in Soil Environments'. (Eds. J.B. Dixon and S.B. Weed) pp.92-159. (Soil Science Society of America: Wisconsin).

Book

Soil Survey Staff (2010). 'Keys to Soil Taxonomy', Eleventh Edition. (U.S.D.A.: Washington, D.C.).

\section{Report/Bulletin}

Sehgal, J., Mandal, D.K., Mandal, C., and Vadivelu, S. (1990). Agro-ecological regions of India. National Bureau of Soil Survey and Land Use Planning, Technical Publication No. 24, Nagpur.

Units : Authors are requested to follow the International System of Units for exact measurements of physical quantities. For complex groupings of units the form such as kg ha-1year-1 may be used.

For exchangeable ions and ion exchange capacity, the recommended unit is $\mathrm{cmol}(+)$ or $(-) \mathrm{kg}-1$, where $(+)$ or $(-)$ refers to unit charge. In tables where reference is being made to both positive and negative charge e.g. cation and anion exchange capacity, the heading $\mathrm{cmol}(+) \mathrm{kg}-1$ can be used with sign made evident by the context. This recommended unit has the advantage of being numerically equivalent to the non-SI but still widely used milliequivalents per $100 \mathrm{~g}$.

For electrical conductivity, the recommended unit is $\mathrm{dSm}-1$.

Soil classification nomenclature: Owing to the international scope of the journal, as well as the most appropriate local classification and soil description methodology, authors should also use internationally recognised soil classification nomenclature such as U.S. Soil Taxonomy or FAO UNESCO.

Statistical evaluation of results: The design and conduct of experiments must be sufficiently explained so that readers 
can judge for themselves the validity of the results. Authors should describe how measurements were made and indicate how treatments were assigned to units or blocks, and the number of replicates.

The experimental design dictates the proper method of statistical analysis and the basis of assessing the precision of treatment means. The precision achieved should be reported by a standard error of the treatment mean or a coefficient of variation. Treatment comparisons such as the least significant difference (lsd) may be made when the variance ratio ( $\mathrm{F}$ value) is significant. Brief analysis of variance (ANOVA) tables with mean squares and degrees of freedom may be published.

Tables must be numbered with arabic numerals and each must be accompanied by a title. Tables should be arranged with regard to the dimensions of the printed page $(12.5$ by $20 \mathrm{~cm})$ and the number of columns kept to a minimum. Excessive sub-division of column headings is undesirable and long headings should be avoided. The first letter only of headings to rows and vertical columns should be capitalised. The symbol for the unit of measurement should be placed in parentheses beneath the column heading. Footnotes should be reserved for specific items in columns. Horizontal rules should be inserted only above and below column headings and at the foot of the table. Vertical rules must not be used. Each table must be referred in the text. Short tables may be incorporated into the text as a sentence or as a brief untitled tabulation.

\section{Illustrations}

Authors should submit lettered line drawings and lettered and mounted photographs which comply with the instructions below. Unsatisfactory figures will be returned for correction.

Line drawings : Original line drawings may be produced using computer graphics with laser printing, or drawn with black ink on white board or on drawing or tracing paper, and with regard to the size of the printed page $(12.5$ by $20 \mathrm{~cm})$. Explanations of symbols used should be given in the caption to the figure. Lettering of the graphs should be kept to a minimum. Grid marks should point inwards; legends to axes should state the quantity being measured and be followed by the appropriate SI units in parentheses.
Photographs : Photographs must be of the highest quality with a full range of tones and of good contrast. Lettering should be in contrast with its background. The size should be such that the final height after reduction is $1.5-2 \mathrm{~mm}$. A scale bar must be inserted on each photomicrograph and electron micrograph. Important features to which attention has been drawn in the text should be indicated. Colour photographs will be accepted if they are essential but the cost of production must be borne by the authors.

\section{Short Communication}

The style of presenting a Short communication is less formal as compared with the 'full-length article'. The sections on Abstract, Materials and Methods, Results and Discussion and Conclusion are omitted but the material is put concisely in the same sequence but without formal sections.

\section{Checklist for preparation of manuscripts}

1. Type of manuscript double - spaced throughout, including references, figure captions and tables.

2. Type the title and all headings aligned left, with only the first letter of the first word and of any proper name capitalised.

3. Main headings (Introduction, Materials and methods, Results and discussion, Acknowledgements, References) are set in bold roman (not italic) type. Minor headings are set in the light italic type.

4. Use the conventions 'from ... to , 'between .... and', 'range $x-y$ '.

5. Check that all references mentioned in the text are in the References, and vice-versa.

6. List references in the text in chronological order, separated by semi-colons. Do not use a comma between the author's name and the date. List references in the References in alphabetical order.

7. Give full journal and book titles in the References. The journal names should be in italics.

8. Use Arabic numerals in the text but in headings spell out numbers less than 10. Type a space between a numeral and its unit (e.g. $3 \mathrm{~mm}$ ).

9. Check that the stippling and/or symbols are legible at the size likely to be used in the published article.

10. Type tables with the title as a separate paragraph.

11. Indicate approximate positions of figures and tables on the manuscript.

12. Check that figures are numbered in the order in which they are discussed in the text. 
13. Suggest a 'short title' for the paper of not more than 50 characters (including spaces).

14. Return the requested number of revised manuscripts; also, return the original manuscript annotated by the editor.

15. Provide email and postal address for the corresponding author.

\section{Correspondence :}

When you submit a manuscript, please provide us with your telephone number, email address as well as your postal address; we may need to contact you urgently.

Address for submissions:

The Honorary Secretary,

Indian Society of Soil Survey and Land Use

Planning,

NBSS\&LUP, Amravati Road,

Nagpur-440 033, INDIA 


\title{
List of Referees - 2016
}

The Editorial Board of the Indian Society of Soil Survey and Land Use Planning, places on record its grateful thanks to the following persons for reviewing the manuscripts during 2016. Without their help and cooperation it would not have been possible to process the manuscripts received for publication in the journal 'Agropedology'.

\author{
AHMED, NAYAN, New Delhi \\ BHAKARE, B.D., Rahuri \\ BRAHMANAND, P.S., Bhubaneshwar \\ CHARY, G.R., Hyderabad \\ CHINCHMALATPURE, ANIL, Bharuch \\ GHOSH, AMLAN, Varanasi \\ ISMAIL, SAYYED, Parbhani \\ JEGADEESWARI, D., Coimbatore \\ JENA, S.K., Bhubaneshwar \\ KALEDHONKAR, M.J., Karnal \\ KATKAR, R.N., Akola \\ KATPATAL, Y.B., Nagpur \\ MANDAL, A.K., Karnal \\ MURTHY, I.Y.L.N., Hyderabad \\ NAGARAJU, M.S.S., Nagpur \\ NAIDU, M.V.S., Tirupati \\ NARALA, ANURADHA, Nagpur \\ PATGIRI, D.K., Guwahati \\ PATIL, MUKUND, Hyderabad \\ RAINA, S.K., Srinagar, \\ SANDAL, S.K., Himachal Pradesh \\ SANTRA, PRIYABRATA, Rajasthan \\ SELVI, D., Coimbatore \\ SINGH, KANIKA, Sydney \\ SRIVASTAVA, P.C., Pantnagar \\ VIJAYAKUMAR, P., Hyderabad
}

